\title{
ANÁLISE MULTITEMPORAL DO USO E OCUPAÇÃO DA TERRA DO CÓRREGO SEM NOME EM ILHA SOLTEIRA/SP.
}

\author{
Aline Cristina Alves da Silva1 \\ Andréia Cruz Rodrigues ${ }^{2}$ \\ Paulo Henrique Vieira ${ }^{3}$
}

Resumo: O presente trabalho tem como objetivo a análise multitemporal do uso e ocupação da terra na bacia hidrográfica do Córrego Sem Nome no município de llha Solteira estado de São Paulo. Para tal análise será utilizado o SIG (Sistema de Informação Geográfico), neste caso específico será utilizado o SPRING 5.2.1, para o auxílio das análises multitemporais nos anos de 2007 e 2013 na área de estudo. Para alcançar o objetivo foi preciso utilizar alguns procedimentos metodológicos dividido em etapas como: levantamento bibliográfico e cartográfico relevante ao assunto e a área, trabalhos de gabinete, procedimentos operacionais, utilização de software, saídas "in loco" e a divulgação dos resultados. Os resultados obtidos no determinado trabalho foram mapas temáticos de uso e ocupação da terra do córrego sem nome. As bacias hidrográficas vêm sofrendo grandes modificações ao longo do tempo, essas modificações quase sempre tem alguma ligação com atividades antrópica.

Palavras-chave: Bacia Hidrográfica. Uso e ocupação. Mapa temático

\footnotetext{
${ }^{1}$ Pós-Graduanda no curso de geografia da UFMS/CPTL. alinegeo ufms@yahoo.com.br

2Pós-Graduanda no curso de geografia da UFMS/CPTL. andreia.delacruzz@gmail.com

${ }_{3}^{3}$ Pós-Graduando no curso de geografia da UFMS/CPTL paulohenrique.vieira@yahoo.com.br
} 


\section{INTRODUÇÃO}

As bacias hidrográficas por ser um local complexo onde ocorram as interações do homem com o meio ambiente vêm sendo local de muitos estudos, principalmente dos geógrafos, considerados especialistas nas atividades antrópicas na superfície. As bacias hidrográficas vêm sofrendo grandes modificações ao longo do tempo, essas modificações quase sempre tem alguma ligação com atividades antrópica. A importância do planejamento sobre bacia hidrográfica fica evidente quando nota-se a quantidade de trabalhos sobre o tema. $O$ total de trabalhos que adotaram B.H. como célula básica foi sete vezes maior na última década (1990/2000) em comparação à década anterior (1980/1990) (BOTELHO \& SILVA apud VITTE \& GUERRA, 2004).

As bacias hidrográficas assumem grande importância na recuperação de áreas degradadas, por vários motivos, um deles é o fato de grande parte dos danos ambientais que ocorrem na superfície terrestre estar situada nas bacias hidrográficas (ARAÚJO et al, 2010).

Os cenários ambientais construídos ou transformados pela ação do homem ocupam a maior parte dos sistemas ambientais. O homem transforma os espaços através de derrubadas de matas, da implantação de pastagens e cultivos, da construção de estradas, portos aeroportos, represas, da retificação e canalização de curso d água, da implantação de indústrias e áreas urbanas. (FLORENZANO 2002).

A adoção da bacia hidrográfica como unidade de planejamento é de aceitação internacional, não apenas porque ela representa uma unidade física bem caracterizada, tanto do ponto de vista de integração como da funcionalidade de seus elementos, mas também porque toda área de terra, por menor que seja, se integra a uma bacia (PISSARRA, 2002).

As imagens de satélite podem ajudar e muito nas transformações que as bacias hidrográficas podem sofrer, através da possibilidade de utilizar imagens de vários anos ou meses, podem-se fazer análises multitemporais e averiguar as mudanças que vêm ocorrendo. 


\section{Then Fórum Ambiental \\ da Alta Paulista \\ ISSN 1980-0827 \\ Volume 9, Número 2, 2013 \\ Bacias Hidrográficas, Planejamento e

Portanto o objetivo proposto por este trabalho é a criação de mapas temáticos de uso e ocupação da terra dos anos de 2007 e 2013, e fazer comparações das coberturas de terra presente no entorno do Córrego Sem Nome.

\section{LOCALIZAÇÃO DA ÁREA DE ESTUDO}

O município de llha Solteira está localizado no noroeste do estado de São Paulo nas margens paulista do Paraná, criado em 30 de Dezembro de 1991. Suas mais antigas referências datam de 30 de Novembro de 1944. Quando tornou-se distrito do município de Pereira Barreto com o nome de Bela Floresta, mas em 8 de maio de 1989 através de uma lei municipal sua sede foi transferida para o então povoado de llha Solteira. Surgiu da necessidade de abrigar os trabalhadores da Companhia Energética de São Paulo (CESP) que iriam trabalhar na construção da Usina Hidroeléctrica de São Paulo.

Essa região precisou desenvolver uma infraestrutura mínima para a construção de alojamentos e vilas operárias para os trabalhadores. Até então o povoado possuía uma rede urbana precária, porque a ocupação da região foi marcada pela pecuária extensiva, pelos latifúndios, pela baixa densidade populacional e pela grande distância dos centros mais significativos. As soluções encontradas para a moradia na região foram diferentes daqueles outros empreendimentos de porte, uma vez que llha optou-se por construir um núcleo urbano residencial permanente. O planejamento urbano foi estabelecido a partir de um zoneamento, baseado em diferentes categorias funcionais e salariais da CESP.

O cenário de estudo o Córrego Sem Nome localiza -se no município de llha Solteira, no estado de São Paulo, sendo integrante da sub-região de Araçatuba. O córrego ao longo dos anos sofreu trágicas modificações, e percorre tanto a área urbana quanto na rural, e durante o trajeto na área urbana teve seu percurso canalizado, afetando assim seu sistema hidrológico e a qualidade ambiental do córrego.

$\mathrm{O}$ acelerado processo de urbanização e o crescimento desordenado das cidades mudam severamente a paisagem, marcada por diferentes processos do meio físico, em geral associados a alguma degradação ambiental (PEDRO \& LORANDI, 2004). 
A figura 1 representa a localização geográfica do Córrego Sem Nome.

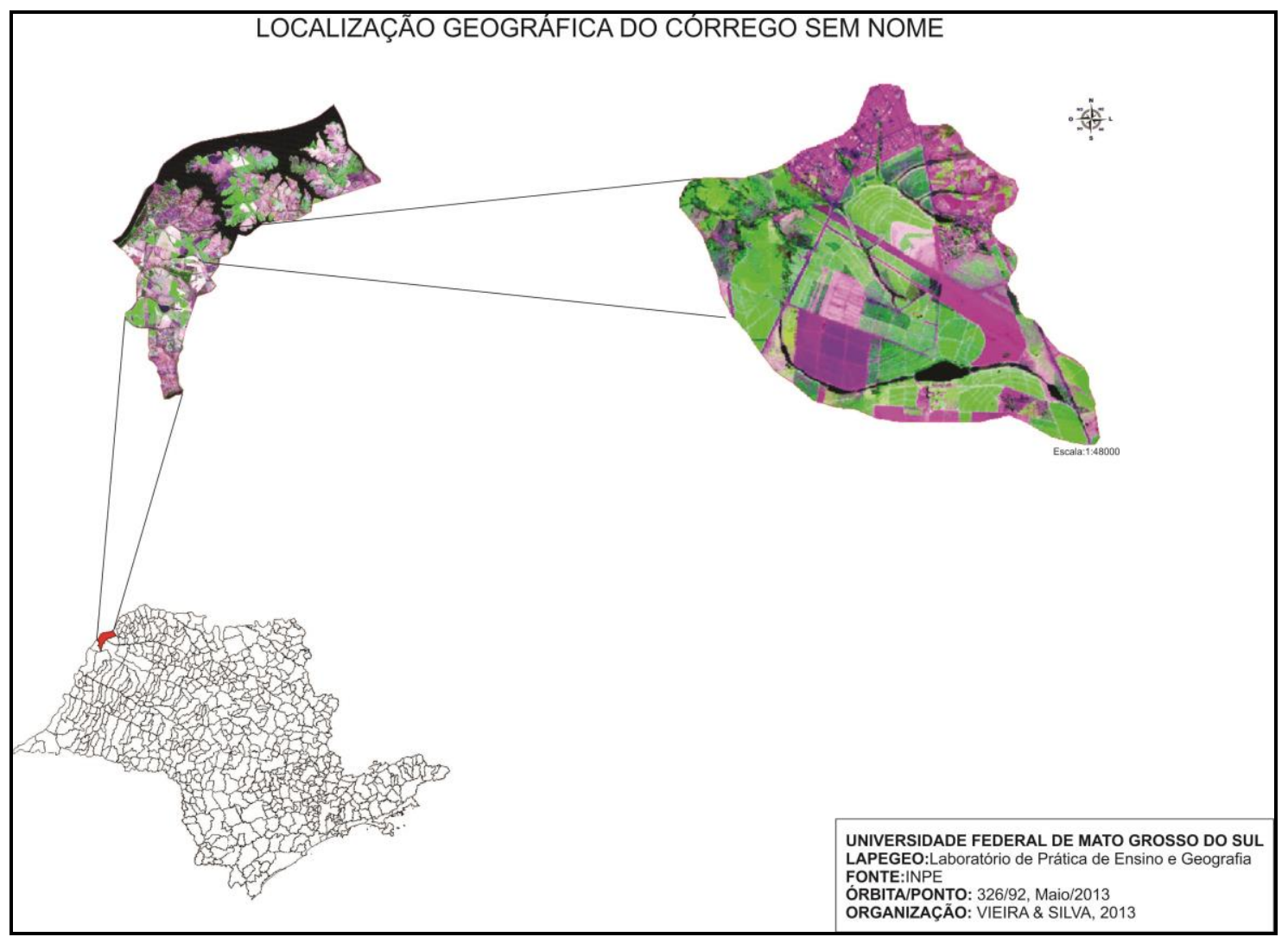

Figura 1 - Localização geográfica do córrego sem nome

Fonte: VIEIRA, P.H e SILVA, A.C.A da.

\section{DESENVOLVIMENTO}

SIG aplicado a gestão ambiental em bacias hidrográficas.

O Córrego Sem nome está situado na cidade de Ilha Solteira localizada na região noroeste do estado de São Paulo, a 652,90 km da capital na Longitude: 51 06' 35" W e Latitude: $20^{\circ} 38^{\prime} 44^{\prime \prime}$.

As etapas do trabalho serão demonstradas a seguir:

Etapa 1 - Levantamento bibliográfico e cartográfico relevante ao assunto e a área. 
Promover compilação das informações disponíveis da bacia em estudo em trabalhos já realizados na área ou em áreas semelhantes e levantamento das características ambientais da área a ser estudada.

\section{Etapa 2 - trabalhos de gabinete}

Verificar quais ferramentas serão aptas para chegar aos objetivos propostos.

\section{Etapa 3 - Utilização de softwares computacionais}

No referido trabalho foi utilizado o software SPRING® 5.2.1, para a produção dos mapas temáticos de uso e ocupação da terra.

\section{Etapa 4 - Procedimentos Operacionais.}

Processamento dos dados orbitais. O software utilizado é o SIG SPRING, para a produção de mapas da bacia hidrográfica do córrego sem nome, com auxílio de imagens de satélite Landsat 5 para o mapa do ano de 2007 e ResourceSat1, que utiliza o sensor LISS 3 para o mapa de 2013.

\section{Etapa 5 - Saídas "in loco"}

Saídas de campo na Bacia Hidrográfica do Córrego Sem Nome para identificação dos tipos de uso e cobertura da terra. Foi feito registro fotográfico de determinados pontos da área de estudo.

\section{Etapa 6 - Organização das Informações.}

Refere-se a organização dos dados adquiridos.

\section{Etapa 7 - Divulgação dos Resultados.}

Informações referentes à bacia hidrográfica do córrego sem nome. 
Os resultados conquistados com este trabalho foram às produções de mapas temáticos de uso e ocupação da terra da bacia hidrográfica do Córrego Sem Nome e suas respectivas análises multitemporais dos anos de 2007 e 2013.

Utilizando o SPRING 5.2.1, foi produzido mapas de uso e ocupação da terra no período de 2007 e 2013. As cores utilizadas nas classes de cobertura da terra são aquelas indicadas pelo IBGE, no Manual Técnico de Uso e Ocupação da Terra (2006).

A bacia hidrográfica do Córrego Sem Nome tem na sua delimitação a área urbana de Ilha Solteira. O sistema hidrológico nas áreas urbanizadas apresenta especificidades em relação às áreas não urbanizadas (áreas de formações vegetais naturais ou cultivadas), onde a ocupação humana é invariavelmente menos intensa e as alterações no ambiente costumam ser em níveis menos acentuados (BOTELHO \& SILVA apud VITTE \& GUERRA, 2004).

A figura 2, mostra o uso e ocupação da terra do Córrego Sem Nome no ano de 2007.

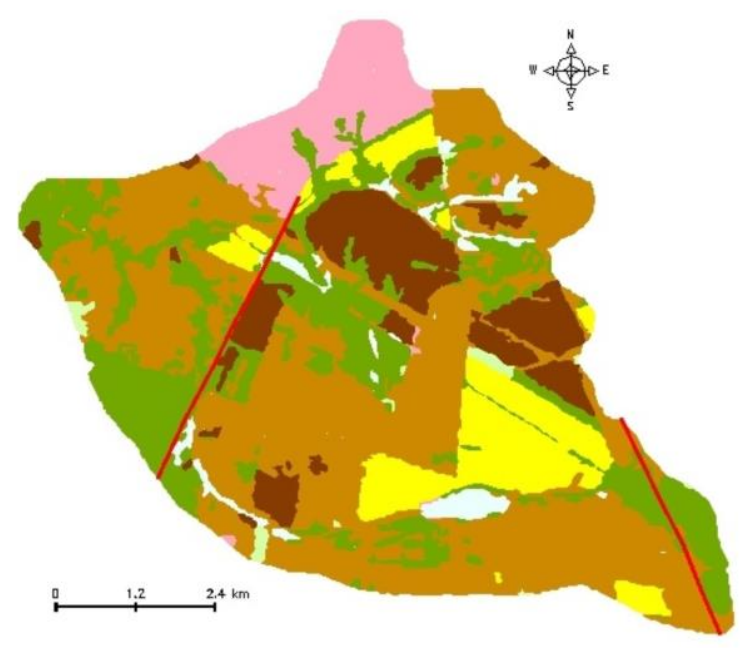

LEGENDA

Área Urbana

Drenagem

Vegetação Florestal

Vegetação Campestre

Pastagem

Solo Exposto

Lavoura Temporária

- Rodovias

UNIVERSIDADE FEDERAL DE MATO GROSSO DO SUL FONTE: DGI, INPE

ORGAIZAÇAOO: VIEIRA \& SILVA, 2013 
Figura 2 - Mapa de uso e ocupação da terra do Córrego Sem Nome/SP-2007.

Fonte: VIEIRA, P.H e SILVA, A.C.A da.

Em 2007, a maior parte da bacia hidrográfica era de pastagem e vegetação florestal com $47 \%$ e $22 \%$ consequentemente da área territorial da bacia.

$\mathrm{Na}$ área encontrava-se também vegetação campestre. Estudos feitos por Paranhos Filho (2008) indicam que esse tipo de vegetação é utilizado para o uso do gado.

No entorno da bacia hidrográfica, encontrava-se lavoura temporária, sendo no município a produção de cana-de-açúcar e também o solo é exposto o qual seria o terreno preparado para a implantação de determinado cultivo, ou seja, a cana-de-açúcar, ambos possuem $10 \%$ cada.

O quadro 1, mostra a porcentagem de cada classe de cobertura.

\begin{tabular}{|c|c|}
\hline Classes de Cobertura & Percentagem (\%) \\
\hline Pastagem & 33 \\
\hline Solo Exposto & 4 \\
\hline Lavoura Temporária & 30 \\
\hline Vegetação & 20 \\
\hline Drenagem & 2 \\
\hline Campestre & 2 \\
\hline Área Urbanizada & 9 \\
\hline Total & 100 \\
\hline
\end{tabular}

Quadro 1 - Porcentagem das classes de 2013.

Fonte: VIEIRA, P.H e SILVA, A.C.A da.

Em 2013 fica evidente a definição de uso e ocupação da terra entre esses períodos. 


\section{MAPA DE USO E OCUPAÇÃO DA TERRA DO CÓRREGO SEM NOME/SP- 2013}
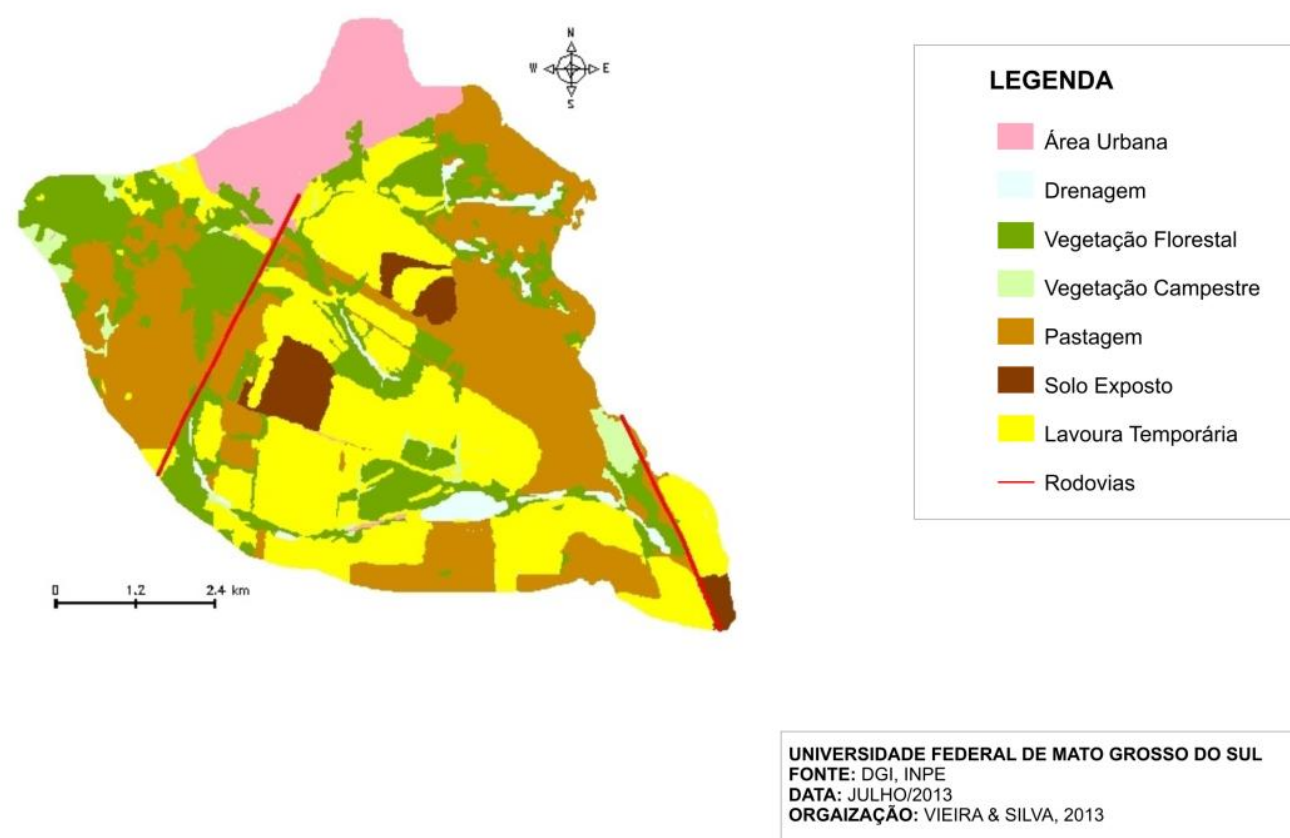

Figura 3 - Mapa de uso e ocupação da terra do Córrego Sem Nome/SP-2013 Fonte: VIEIRA, P.H e SILVA, A.C.A da.

Nota-se o aumento da cana-de-açúcar de $10 \%$ para $30 \%$, com o adicional de solo exposto de $4 \%$, torna-se a classe de cobertura da terra com maior parcela territorial, já que a pastagem possui agora $33 \%$ da área.

Outra mudança ocorrida foi no processo de canalização do Córrego Sem Nome na área urbana, afetando assim seu trajeto. No percurso urbano o assoreamento do córrego e acumulo de lixo é visível, afetando o equilíbrio e a qualidade ambiental do córrego.

Outras classes de cobertura da terra como drenagem, vegetação florestal e campestre, tiveram pequenas mudanças, como mostra o quadro 2. 


\begin{tabular}{|c|c|}
\hline Classes de Cobertura & Percentagem (\%) \\
\hline Pastagem & 47 \\
\hline Solo Exposto & 10 \\
\hline Lavoura Temporária & 10 \\
\hline Vegetação & 22 \\
\hline Drenagem & 2 \\
\hline Campestre & 1 \\
\hline Área Urbanizada & 8 \\
\hline Total & 100 \\
\hline
\end{tabular}

Quadro 1 - Porcentagem das classes de cobertura 2007.

Fonte: VIEIRA, P.H e SILVA, A.C.A da

\section{CONCLUSÃO}

As pesquisas que utilizam SIG (Sistema de Informação Geográfica) como ferramenta para auxílio do usuário vem aumentando nos últimos anos, principalmente pelo custo benefício que o SIG proporciona, minimizando custo e tempo, obtendo resultados satisfatórios.

Outro fator para a popularização do seu uso é a quantidade de softwares disponíveis como ArcGis, ArcVieu e outros disponíveis gratuitamente como ILWIS e SPRING, sendo o SPRING programa totalmente em português, produzido pelo INPE (Instituto Nacional de Pesquisas Espaciais), que também disponibilizam em seu site imagens de satélite, que podem ser adquiridas gratuitamente como LANDSAT e CBERS.

O SIG demonstrou ser uma ferramenta fundamental nas análises multitemporais e ambientais que tiveram seu uso e ocupação da terra modificado maximizando os resultados.

\section{REFERÊNCIAS}

ARAÚJO, G. H. S; ALMEIDA, J. R de; GUERRA, A.J.T. Gestão ambiental de áreas degradadas. $6^{\underline{a}}$ ed. - Rio de Janeiro: Bertrand Brasil, 2010. 
BOTELHO, R.G.M; SILVA, A.S da. Bacia hidrográfica e qualidade ambiental. Cap.6, 2004 In: VITTE, Antônio Carlos e GUERRA, Antônio José Teixeira (org.). Reflexões Sobre a Geografia Física no Brasil. Rio de Janeiro: Bertrand Brasil, 2004.

FLORENZANO, Tereza Galloti. Imagens de satélite para estudos ambientais. São Paulo: Oficina de Textos, 2002.

IBGE - Instituto Brasileiro de Geografia e Estatística. Cidades. Disponível em: $<$ www.ibge.gov.br>. Acesso em Setembro de 2013.

IBGE. Manual Técnico do Uso da Terra. Ed.2, n.7. Rio de Janeiro, 2006.

MAGALHÃES, L. Z de. Problemas ambientais de uma cidade média de Mato Grosso: o caso de Barra do Bugre. Dissertação (mestrado), Universidade Federal de Mato Grosso, Cuiabá (MT), 2007.

PEDRO, F. G.; LORANDI, R. Potencial natural de erosão na área periurbana de São Carlos SP. Revista Brasileira de Cartografia, v.56, 2004.

PISSARRA, T. C. T. Análise da Bacia Hidrográfica do Córrego Rico na sub-região de Jaboticabal, SP: Comparação entre imagens TM-LANDSAT 5 e Fotografias aéreas verticais. $136 \mathrm{f}$. Tese (Doutorado em Produção Vegetal) - Faculdade de Ciências Agrárias e Veterinárias, Universidade Estadual Paulista, Jaboticabal, 2002. 